\title{
Tungsten as a Chemically-Stable Electrode Material on Ga-Containing Piezoelectric Substrates Langasite and Catangasite for High-Temperature SAW Devices
}

\author{
Gayatri K. Rane ${ }^{1, *}$, Marietta Seifert ${ }^{1}$, Siegfried Menzel ${ }^{1}$, Thomas Gemming ${ }^{1}$ and \\ Jürgen Eckert ${ }^{2,3}$ \\ 1 SAWLab Saxony, IFW Dresden, 27011601171 Dresden, Germany; marietta.seifert@ifw-dresden.de (M.S.); \\ s.menzel@ifw-dresden.de (S.M.); t.gemming@ifw-dresden.de (T.G.) \\ 2 Erich Schmid Institute of Materials Science, Austrian Academy of Sciences (ÖAW), Austria \\ 3 Department Materials Physics, Montanuniversität Leoben, 12 A-8700 Leoben, Austria; \\ juergen.eckert@unileoben.ac.at \\ * Correspondance: g.k.rane@ifw-dresden.de; Tel.: +49-351-4659-842
}

Academic Editor: Luciano Feo

Received: 5 January 2016; Accepted: 4 February 2016; Published: 6 February 2016

\begin{abstract}
Thin films of tungsten on piezoelectric substrates $\mathrm{La}_{3} \mathrm{Ga}_{5} \mathrm{SiO}_{14}$ (LGS) and $\mathrm{Ca}_{3} \mathrm{TaGa}_{3} \mathrm{Si}_{2} \mathrm{O}_{14}$ (CTGS) have been investigated as a potential new electrode material for interdigital transducers for surface acoustic wave-based sensor devices operating at high temperatures up to $800{ }^{\circ} \mathrm{C}$ under vacuum conditions. Although LGS is considered to be suitable for high-temperature applications, it undergoes chemical and structural transformation upon vacuum annealing due to diffusion of gallium and oxygen. This can alter the device properties depending on the electrode nature, the annealing temperature, and the duration of the application. Our studies present evidence for the chemical stability of $\mathrm{W}$ on these substrates against the diffusion of $\mathrm{Ga} / \mathrm{O}$ from the substrate into the film, even upon annealing up to $800{ }^{\circ} \mathrm{C}$ under vacuum conditions using Auger electron spectroscopy and energy-dispersive X-ray spectroscopy, along with local studies using transmission electron microscopy. Additionally, the use of CTGS as a more stable substrate for such applications is indicated.
\end{abstract}

Keywords: high temperature sensor; surface acoustic wave devices; electrode material; refractory metal thin film

\section{Introduction}

Surface acoustic wave (SAW) devices have exhibited promising application as sensors for monitoring and controlling high temperatures above $400{ }^{\circ} \mathrm{C}$ and are increasingly demanded due to their functionality provided by their small size, robustness, and unique capability for wireless interrogation under extreme environments [1-4]. However, for high-temperature applications above $500{ }^{\circ} \mathrm{C}$, several issues are related to the choice of durable materials for the interdigital transducer (IDT) thin film electrode and the piezoelectric substrate for enabling long-term applicability, such as:

- Chemical and structural stability of film-substrate composite in harsh environments;

- Resistance to stress-induced damaging effects in the nanocrystalline thin film electrode, such as agglomeration, delamination, creep, etc. These effects are enhanced at higher temperatures due to the dissimilar coefficient of thermal expansion (CTE) of the materials in contact.

- Low and stable electrical resistivity of the electrodes at the operating temperatures.

For over a decade, the piezoelectric substrate $\mathrm{La}_{3} \mathrm{Ga}_{5} \mathrm{SiO}_{14}$ (LGS) has been investigated extensively at high temperatures for application in SAW sensors in harsh environments under an 
air atmosphere [5-10]. However, recent studies have revealed chemical instability of LGS and its high sensitivity to different surrounding atmospheres. Especially under vacuum or at low oxygen partial pressures, a high rate of diffusion of oxygen and gallium atoms was observed already at about $700{ }^{\circ} \mathrm{C}$ [11-14]. This diffusion also affects the metal electrode, e.g., oxidation of Ir IDT upon annealing in vacuum was observed due to the diffusion of oxygen from the LGS substrate into the Ir thin film [13]. In addition to being unstable in vacuum, recent studies on Pt-based IDTs on LGS exhibit the presence of gallium in the electrode film also upon annealing in air [15]. Deposition of a covering alumina layer on top of the LGS substrate hindered the diffusion of $\mathrm{Ga} / \mathrm{O}$ out from the substrate to a certain extent in this case. Ga and Pt can form various phases according to the phase diagram [16], suggesting that the inherent instability of the LGS substrate could be one of the reasons for the deterioration of the $\mathrm{Pt}$ films.

It is well-established now that diffusion of $\mathrm{Ga}$ and $\mathrm{O}$ takes place during high temperature annealing in low-oxygen partial-pressure environments. In addition, studies by Aubert et al. [17] have also shown that severe surface modification which revealed itself as high density of visible flaws on the surface were observed upon annealing bare LGS substrates in air at $1200{ }^{\circ} \mathrm{C}$. These flaws were severely Ga-depleted. Bardong et al. [11] observed the degradation of the crystals when annealed in both air and vacuum. Degradation in vacuum occurred already at $480{ }^{\circ} \mathrm{C}$ and was attributed to the loss of gallium oxide. Recent studies in our group present a detailed investigation on LGS substrate upon annealing at $800{ }^{\circ} \mathrm{C}$ under vacuum [18]. Substrate modification by the formation of microcracks on the surface with strongly altered chemical composition was evidenced.

Another high-temperature stable piezoelectric substrate of the same LGS family is $\mathrm{Ca}_{3} \mathrm{TaGa}_{3} \mathrm{Si}_{2} \mathrm{O}_{14}$ (CTGS) [19-21]. This material has better piezoelectric properties, such as higher effective piezoelectric coefficient at high temperature. The crystals have better quality due to the lower Ga content, higher electrical resistivity, higher mechanical strength and a lower thermal expansion anisotropy as compared to langasite [20-23]. This relatively newer substrate material is lesser known and thin films on it are not extensively studied yet. Our studies on RuAl films [24] and W films [25] on CTGS showed that while the latter system was stable up to $800^{\circ} \mathrm{C}$, the former was degraded similar to that on LGS, but to a lesser extent.

In this paper, the in-depth studies on tungsten thin films as IDT material on piezoelectric substrates of LGS and CTGS is presented up to $800{ }^{\circ} \mathrm{C}$ under vacuum. The choice of refractory metal $\mathrm{W}$, over the commonly used inert $\mathrm{Pt}$, is based on it having a high melting point $\left(3422{ }^{\circ} \mathrm{C}\right)$ which would lead to minimal creep-related damaging effects (the activation energy for self-diffusion at $1000{ }^{\circ} \mathrm{C}$ for $\mathrm{W}$ is $\sim 6 \mathrm{eV}$ while for $\mathrm{Pt}$ is $\sim 3 \mathrm{eV}$ [26]), its lower electrical resistivity $(5.49 \mu \Omega \cdot \mathrm{cm})$ as compared to Pt $(10.6 \mu \Omega \cdot \mathrm{cm})$, closer CTE $\left(4.5 \times 10^{-6} \mathrm{~K}\right)$ to LGS $\left(\mathrm{a}_{11}=5.63 \times 10^{-6} \mathrm{~K}\right)$ and CTGS $\left(\mathrm{a}_{11}=3.3 \times 10^{-6} \mathrm{~K}\right)$ [20] than for Pt $\left(8.8 \times 10^{-6} \mathrm{~K}\right)$. In addition, $\mathrm{W}$ has exceptional thermal shock resistance due to its low CTE combined with its high thermal conductivity $\left(174 \mathrm{~W} \cdot \mathrm{m}^{-1} \cdot \mathrm{K}^{-1}\right)$ which for $\mathrm{Pt}$ is much lower $\left(72 \mathrm{~W} \cdot \mathrm{m}^{-1} \cdot \mathrm{K}^{-1}\right)$ [27].

Former studies in the group have been performed on $\mathrm{W}, \mathrm{W} / \mathrm{Mo}$, and $\mathrm{RuAl}$ systems as electrode material on LGS and CTGS [25,28]. Upon vacuum annealing of the films up to $800{ }^{\circ} \mathrm{C}$, oxidation of the $\mathrm{RuAl}$ and presence of $\mathrm{Ga}$ in the film was detected for the films on both LGS and CTGS. In contrast, the extent of degradation of W on LGS was much lower, while a very high stability was observed for W on CTGS. The degradation of RuAl film was attributed to the diffusion of $\mathrm{Ga} / \mathrm{O}$ from both the substrates into the thin film upon vacuum annealing. Since $\mathrm{W}$ was unaffected by Ga/O diffusion, we delved deeper to gather an understanding of the properties of the film-substrate upon annealing in vacuum by detailed investigations using Auger electron spectroscopy and transmission electron microscopy. The results of the local analysis of the films are provided in this short communication.

The application of the electrodes is presently restricted to vacuum and inert atmospheres since application in different environments would require a passivating layer to avoid degradation of the electrode. Thus, low-cost materials exhibiting high-temperature stability, such as W or Mo, are studied rather than the Pt-based electrodes. Our studies are directed towards lab-scale applications in vacuum process chambers (thin film deposition chambers where SAW sensors can be attached to the substrate) 
or where precise and real-time temperature measurements are required (phase transformation studies, reaction thermodynamics, etc.). In addition to these, applications can also be thought in other fields which perform tests in vacuum, e.g., NASA uses thermo-vacuum chambers for conducting tests on aircraft and spacecraft systems and components [29].

\section{Experimental Section}

$100 \mathrm{~nm}$ films of $\mathrm{W}$ were deposited by DC magnetron sputtering onto LGS and CTGS substrates at $400{ }^{\circ} \mathrm{C}$ under high vacuum conditions (at a pressure of $1.8 \times 10^{-4} \mathrm{~Pa}$ from a 99.95\% pure target using 99.999\% Ar sputtering gas). The commercially available (FOMOS-Materials, Moscow) LGS (138.5 $5^{\circ}$ Y-cut wafer of $4^{\prime \prime}$ diameter) and CTGS (90 Y-cut wafer of $3^{\prime \prime}$ diameter) wafers of $500 \mu \mathrm{m}$ thickness (surface finish according to IEC 2005) were used as obtained. The films were deposited onto $10 \times 10 \mathrm{~mm}$ cut wafer pieces thereof. The samples were annealed at 400,600 , and $800{ }^{\circ} \mathrm{C}$ each for $12 \mathrm{~h}$ under high vacuum $\left(10^{-3} \mathrm{~Pa}\right)$ conditions. All the measurements have been performed at room temperature after the annealing process.

The films have been investigated by X-ray diffraction (XRD, Philips (now PANalytical) X'Pert PW3040/00, Co-K $\alpha$, PANalytical, Almelo, The Netherlands) in Bragg-Brentano geometry. Depth profiles of the atomic concentration were recorded using Auger electron spectroscopy (AES, JEOL JAMP-9500F Field Emission Auger Microprobe, $1 \mathrm{kV} \mathrm{Ar}{ }^{+}$ions at $0.7 \mu \mathrm{A}$, JEOL, Tokyo, Japan).

The surface of the substrates and substrate-film systems were analyzed by scanning electron microscopy (SEM, Zeiss Ultra Plus, Carl Zeiss Microscopy GmbH, Jena, Germany) and atomic force microscopy [AFM, DI Dimension 3100, Bruker (formerly Digital Instruments), Billerica, MS, USA]. Cross sections of the samples have been prepared by the focued ion beam technique (FIB, Zeiss 1540 XB CrossBeam, Carl Zeiss Microscopy GmbH, Jena, Germany).

High-angle annular dark-field scanning transmission electron microscopy (HAADF-STEM, FEI Technai F30, FEI, Hillsboro, OR, USA) was performed to analyze the microstructure on the nanoscale. Together with energy dispersive X-ray spectroscopy (EDX, EDAX, Mahwah, NJ, USA) in the same instrument, the local chemical composition has been determined.

\section{Results and Discussion}

X-ray diffraction measurements show that the as-deposited $W$ films on both the substrates consist of predominantly $\{110\}$ oriented $\alpha-W$ grains with the out-of-plane coherently diffracting domain size of about $35 \mathrm{~nm}$ [30]. The electrical resistivity (van der Pauw method) of the as-deposited $W$ film on LGS was $15.4 \mu \Omega \cdot \mathrm{cm}$ and that on CTGS was $14.3 \mu \Omega \cdot \mathrm{cm}$. The electrical resistivity of the W films after vacuum annealing at 400,600, and $800^{\circ} \mathrm{C}$ for $12 \mathrm{~h}$ each are shown in Figure 1 (measurements were performed at room temperature after the particular annealing steps).

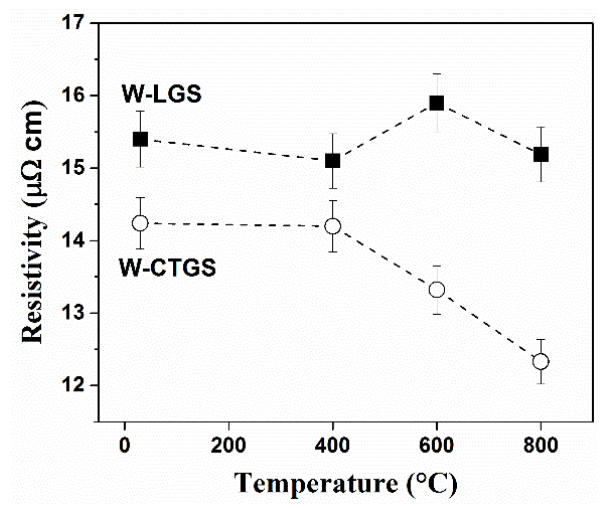

Figure 1. Electrical resistivity upon annealing $100 \mathrm{~nm} \cdot \mathrm{W}$ films on LGS and CTGS at $400{ }^{\circ} \mathrm{C}, 600{ }^{\circ} \mathrm{C}$, and $800{ }^{\circ} \mathrm{C}$ for $12 \mathrm{~h}$ each under vacuum (a maximum error of $<5 \%$ is considered due to fluctuation in the voltage). 
The samples annealed at $400{ }^{\circ} \mathrm{C}$ exhibit no change in the resistivity. Upon annealing to $600{ }^{\circ} \mathrm{C}$, while the resistivity of W on CTGS reduced, no change was observed for the films on LGS. The final resistivity of W-LGS after annealing to $800{ }^{\circ} \mathrm{C}$ was almost unchanged, whereas approximately $10 \%$ reduction was observed for W-CTGS.

XRD measurements after annealing W-LGS at $600{ }^{\circ} \mathrm{C}$ and $800{ }^{\circ} \mathrm{C}$ for $12 \mathrm{~h}$, show a continual sharpening of the (100) reflection. Single line analysis [31] on this sample indicated an increase of the grain size. Alongside, the intensity of other reflections increases indicating the loss of any preferred orientation. Similar to W-LGS, the reflections of the W film on CTGS also become narrower (due to grain growth and defect annihilation); however, a sharper $\{110\}$ preferred orientation of the grains develops in this sample. Grain growth and improved grain orientation should lead to the decrease of the electrical resistivity in the $\mathrm{W}$ films on CTGS.

In order to understand the indiscernible electrical resistivity evolution of W on LGS upon annealing, microstructural investigations were carried out on the samples heated up to $800{ }^{\circ} \mathrm{C}$ using SEM. Low magnification SEM images of the W-LGS system (Figure 2a) showed severe surface damage manifested as scattered blisters over the entire film surface. In contrast, no defects were observed on the W-CTGS film surface (Figure $2 b$ ) and the surface roughness (RMS value) as measured by atomic force microscope (AFM, DI Dimension 3100) was $1.7 \mathrm{~nm}$ for this film. The microstructures of the two films, however, are similar in the non-defected regions (see inset in Figure 2 for high-magnification SEM images).
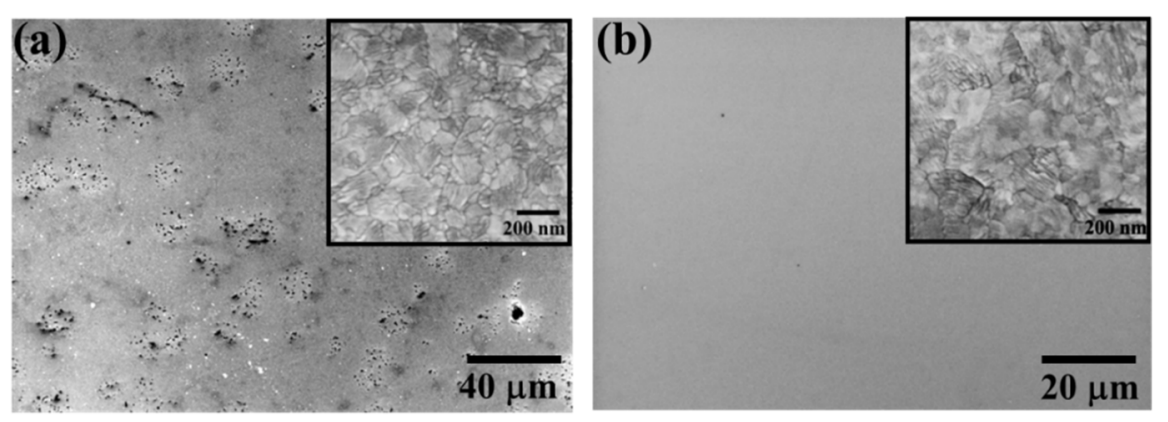

Figure 2. Low magnification SEM images of $\mathrm{W}$ films on (a) LGS and (b) CTGS post-annealing at $800{ }^{\circ} \mathrm{C}$ for $12 \mathrm{~h}$ under vacuum (high-magnification images are shown in the inset).

AES measurements were performed on these two samples (Figure 3) to gather information on the presence of contaminants in the films. Samples were rotated to minimize roughening effects. Measurements on W-LGS were performed at different locations, i.e., at the blistered location as well as on the smoother region. Measurements at the blistered locations (shown in Figure $3 b$ ), shows the presence of $\mathrm{La}$ and $\mathrm{Ga}$ in addition to $\mathrm{C}$ and $\mathrm{O}$ in the depths of the film. Depth profiling the blistered location showed a high carbon content ( 5 at.\%) within the film. However, measurements at the smoother regions (shown in Figure 3a) show surface contamination of only $\mathrm{C}$ and $\mathrm{O}$ and no contamination in the depths of the film. In comparison, the depth profile of the W-CTGS sample at several locations show no contaminants within the film (Figure 3c). The surface of this film shows the presence of only $\mathrm{C}$ and $\mathrm{O}$. The presence of La and Ga near the surface regions at the blistered locations on W-LGS indicates that the substrate undergoes changes.

Thus, several FIB-cuts were made at the blistered region, perpendicular to the film surface, on the annealed W-LGS sample to understand the origin of these blistered defects. Figure 4 shows one such FIB-cut with a visible protruding "blister". It can be seen from this figure that the substrate region just below the film has varying contrasts indicating a change in the substrate composition. Furthermore, a grain (see image) is seen pushed upwards close to this blister region. Sequential FIB-cuts in this region showed that the blister originated from the substrate leading to not only "pushing-out" of individual grains but also disrupting regions in the deposited film and the loss of continuity of the film on the 
substrate. Thus, the $\mathrm{W}$ film was absent at the regions of the blister due to the outwards flow of the substrate material.
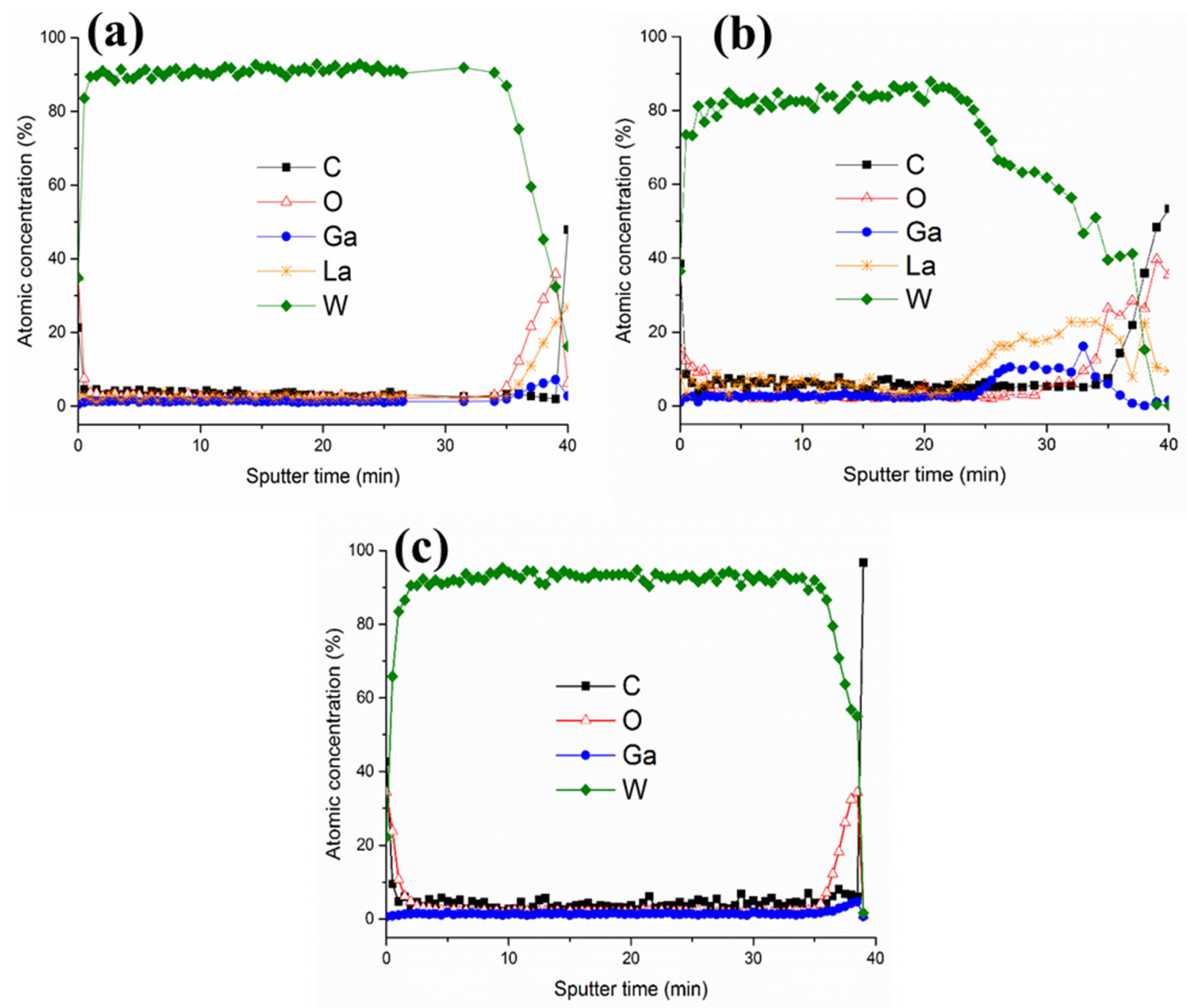

Figure 3. AES depth profiles made at (a) non-defected region on W-LGS, (b) around the blister location on W-LGS, and (c) on W-CTGS.

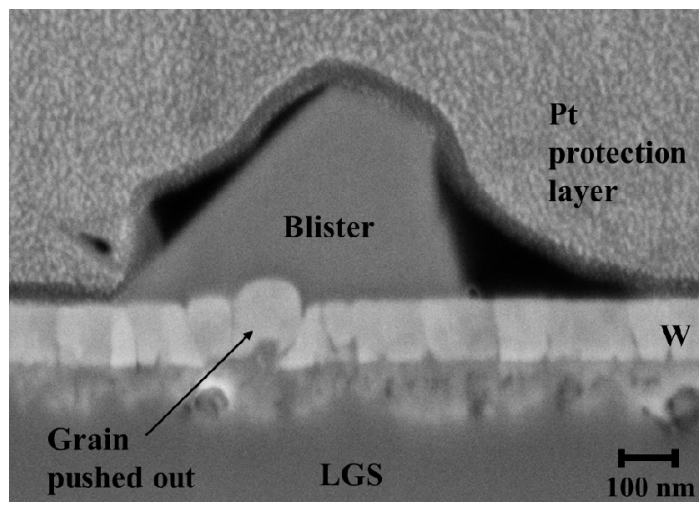

Figure 4. FIB-cut around the blistered area on W-LGS after annealing to $800{ }^{\circ} \mathrm{C}$ showing a grain pushed out.

In order to understand these defects that developed on the film on LGS after annealing up to $800{ }^{\circ} \mathrm{C}$, TEM studies were performed on a lamellae at the blistered surface region, as shown in 
Figure 5a,b. It can been seen in Figure 5a that while the film in this region looks intact, high contrasts are visible in the LGS substrate just below the film interface. A local analysis of the chemical composition with EDX on the substrate close to the film interface revealed severe changes in the composition of the substrate (see position 3 and 4 in Figure 5a, and the corresponding composition in Table (a)). In particular, these regions were either entirely depleted of Ga or had diminished Ga content. The stoichiometric composition of the substrate was retained in the depths of the substrate (position 2). Interestingly, the W film composition (Table (a), Region 1) is unaffected as was also suggested by the AES measurements. Further on, no oxidation of the W-LGS film can be detected from the EDX analysis. Another position on the same lamella is showed in Figure $5 b$ having the blister as seen protruding on the film surface (Figure 5b, Region 1). This grey region on top of the film surface is composed of predominantly La, Si and O (inset table). As mentioned above, AES measurements at the blistered regions also showed the presence of La.
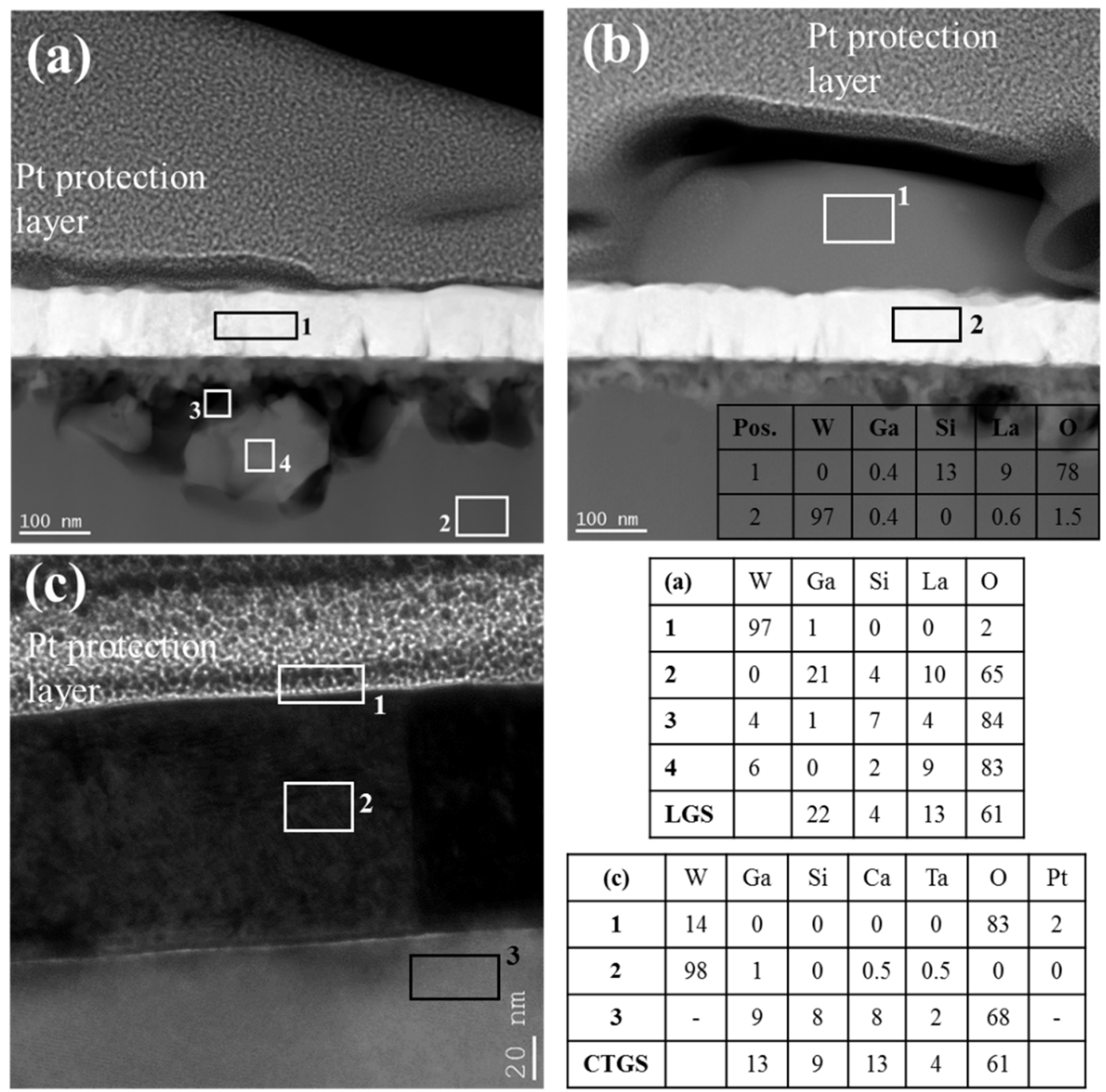

\begin{tabular}{|l|l|l|l|l|l|}
\hline (a) & W & Ga & Si & La & O \\
\hline $\mathbf{1}$ & 97 & 1 & 0 & 0 & 2 \\
\hline $\mathbf{2}$ & 0 & 21 & 4 & 10 & 65 \\
\hline $\mathbf{3}$ & 4 & 1 & 7 & 4 & 84 \\
\hline $\mathbf{4}$ & 6 & 0 & 2 & 9 & 83 \\
\hline LGS & & 22 & 4 & 13 & 61 \\
\hline
\end{tabular}

\begin{tabular}{|c|c|c|c|c|c|c|c|}
\hline (c) & $\mathrm{W}$ & $\mathrm{Ga}$ & $\mathrm{Si}$ & $\mathrm{Ca}$ & $\mathrm{Ta}$ & $\mathrm{O}$ & $\mathrm{Pt}$ \\
\hline $\mathbf{1}$ & 14 & 0 & 0 & 0 & 0 & 83 & 2 \\
\hline $\mathbf{2}$ & 98 & 1 & 0 & 0.5 & 0.5 & 0 & 0 \\
\hline $\mathbf{3}$ & - & 9 & 8 & 8 & 2 & 68 & - \\
\hline CTGS & & 13 & 9 & 13 & 4 & 61 & \\
\hline
\end{tabular}

Figure 5. TEM images along with the composition (table inset) of the marked regions obtained by EDX analysis of (a) W-LGS; (b) W-LGS showing the blister; and (c) W-CTGS.

The TEM image of the W-CTGS system is shown in Figure 5c. Columnar grains of W spanning the film thickness and a sharp interface in between the film and the substrate was confirmed from a view of a number of images. EDX analysis (Table (c)) reconfirms the purity of the W film. The composition of the substrate obtained from EDX conforms closely to that of stoichiometric CTGS single crystals. 
Thus, the W-CTGS system is rather stable with respect to the film structure, as well as the chemical stability of the substrate.

The destroyed architecture of the W-LGS system can be understood to be a consequence of the instability of LGS substrate under vacuum conditions leading to severe surface modifications, as was already reported by us [18]. Upon annealing, several microcracks on the substrate were visible (Figure 4 in reference [18]). When material with high affinity to oxygen was deposited on LGS, such as $\mathrm{RuAl}$, and annealed in vacuum, severe oxidation of the film took place, and the presence of $\mathrm{Ga}$ in the film was detected. In contrast to $\mathrm{RuAl}$, in the present study, although visual damages in the film and substrate can be identified, the structural damages are independent of chemical changes in the W film (as confirmed by EDX and AES). This could be attributed to the relatively low affinity of oxygen to $\mathrm{W}$ as compared to for $\mathrm{Ga}$. One possible explanation for this could be the higher stability of the gallium oxide [32] as compared to tungsten oxide [33] at low oxygen partial pressures, according to the Ellingham diagram. Additionally, $\mathrm{W}$ and $\mathrm{Ga}$ (as well as La) are mutually immiscible and do not form any phases, according to the phase diagram [34].

Thus, upon annealing W films on LGS, under vacuum, blister-like features were observed which originate at the substrate as a result of gallium oxide diffusion. The material displaced from LGS goes through the film at the grain boundaries (easy diffusion paths) disturbing the film continuity. Such local defects in the film offer additional scattering contribution to the flow of electrons and, hence, can explain the anomalous resistivity evolution on LGS.

In comparison to LGS, we observe that the CTGS substrate (which has lower Ga content and is a more ordered structure) is more stable for applications under vacuum conditions. The $\mathrm{W}$ film-CTGS substrate composite are stable, chemically and structurally, up to $800^{\circ} \mathrm{C}$ under vacuum.

\section{Conclusions}

W films on LGS develop defects when annealed under vacuum due to the instability of the LGS substrate with respect to gallium oxide diffusion. The chemical changes in LGS were accompanied by the development of structural defects in the substrate that led to the deterioration of the W film architecture on LGS. The chemical instability of the LGS substrate was, however, inconsequential to the chemical stability of the W film. However, the inherent instability of the LGS substrate would pose a problem in its utilization for high-temperature applications. In contrast to LGS, the CTGS substrate with the $\mathrm{W}$ film on it were stable, chemically, as well, as structurally, up to a temperature of $800^{\circ} \mathrm{C}$ under vacuum. Thus, tungsten, with its relevant properties as an electrode material, is an interesting candidate for IDTs on the Ga-containing substrate LGS and CTGS for application under vacuum up to $800^{\circ} \mathrm{C}$.

Acknowledgments: Financial support by German BMBF (InnoProfile-Transfer grant 03IPT610Y) is gratefully acknowledged. The authors would like to express their gratitude to E. Brachmann for help with the thin film depositions, T. Wiek for FIB preparation and M. Hoffmann for AES measurements.

Author Contributions: Gayatri Rane conceived and designed the experiments, performed the SEM, XRD, AFM measurements and mainly analyzed the data. Marietta Seifert contributed to the analysis and evaluation of the data on the substrate. Thomas Gemming performed the TEM measurements and analysis. Siegfried B Menzel supported discussion. The paper was written by Gayatri Rane with the help of the co-authors.

Conflicts of Interest: The authors declare no conflict of interest.

\section{References}

1. Mrosk, J.W.; Ettl, C.; Berger, L.; Dabala, P.; Fecht, H.J.; Dommann, A.; Fischerauer, G.; Hornsteiner, J.; Riek, K.; Riha, E.; et al. SAW sensors for high temperature applications. In Proceedings of the 24th Annual Conference of the IEEE Industrial Electronics Society, Aachen, Germany, 1-4 August 1998; pp. 2386-2390.

2. Da Cunha, M.P.; Moonlight, T.; Lad, R.; Frankel, D.; Bernhard, G. High temperature sensing technology for applications up to $1000^{\circ} \mathrm{C}$. In Proceedings of IEEE Sensors, Lecce, France, 26-29 October 2008; pp. 752-755. 
3. Elmazria, O.; Aubert, T. Wireless SAW sensor for high temperature applications: Material point of view. In Smart Sensors, Actuators, and MEMS V, SPIE Proceedings; Schmid, U., SánchezRojas, J.L., Leester-Schaedel, M., Eds.; SPIE: Bellingham, WA, USA, 2011; Volume 806602.

4. Jiang, X.N.; Kim, K.; Zhang, S.J.; Johnson, J.; Salazar, G. High-Temperature Piezoelectric Sensing. Sensors 2014, 14, 144-169. [CrossRef] [PubMed]

5. Thiele, J.A.; Da Cunha, M.P. Platinum and palladium high-temperature transducers on langasite. IEEE Trans. Ultrason. Ferroelectr. Freq. Control 2005, 52, 545-549. [CrossRef] [PubMed]

6. Pereira da Cunha, M.; Lad, R.J.; Moonlight, T.; Bernhardt, G.; Frankel, D.J. High temperature stability of langasite surface acoustic wave devices. In Proceedings of the IEEE International Ultrasonics Symposium, Beijing, China, 2-5 November 2008; pp. 205-208.

7. Richter, D.; Sakharov, S.; Forsen, E.; Mayer, E.; Reindl, L.; Fritze, H. Thin film electrodes for high temperature surface acoustic wave devices. Procedia Eng. 2011, 25, 168-171. [CrossRef]

8. Sakharov, S.; Roshchupkin, D.; Emelin, E.; Irzhak, D.; Buzanov, O.; Zabelin, A. X-ray diffraction investigation of high-temperature SAW-sensor based on LGS crystal. Procedia Eng. 2011, 25, 1020-1023. [CrossRef]

9. Aubert, T.; Elmazria, O.; Assouar, B.; Bouvot, L.; Hehn, M.; Weber, S.; Oudich, M.; Geneve, D. Behavior of platinum/tantalum as interdigital transducers for SAW devices in high-temperature environments. IEEE Trans. Ultrason. Ferroelectr. Freq. Control 2011, 58, 603-610. [CrossRef] [PubMed]

10. Bardong, J.; Aubert, T.; Naumenko, N.; Bruckner, G.; Salzmann, S.; Reindl, L.M. Experimental and theoretical investigations of some useful langasite cuts for high-temperature SAW applications. IEEE Trans. Ultrason. Ferroelectr. Freq. Control 2013, 60, 814-823. [CrossRef] [PubMed]

11. Bardong, J.; Bruckner, G.; Kraft, M.; Fachberger, R. Influence of packaging atmospheres on the durability of high-temperature SAW sensors. In Proceedings of the IEEE International Ultrasonics Symposium, Rome, Italy, 20-23 September 2009; pp. 1680-1683.

12. Fritze, H. High-temperature piezoelectric crystals and devices. J. Electroceram. 2011, 26, 122-161. [CrossRef]

13. Aubert, T.; Bardong, J.; Elmazria, O.; Bruckner, G.; Assouar, B. Iridium interdigital transducers for high-temperature surface acoustic wave applications. IEEE Trans. Ultrason. Ferroelectr. Freq. Control 2012, 59, 194-197. [CrossRef] [PubMed]

14. Fritze, $\mathrm{H}$. Electromechanical properties and defect chemistry of high-temperature piezoelectric materials. Habilitation Thesis, Technical University Clausthal, Saxony, Germany, 2007.

15. Moulzolf, S.; Frankel, D.; Pereira da Cunha, M.; Lad, R. High temperature stability of electrically conductive $\mathrm{Pt}-\mathrm{Rh} / \mathrm{ZrO}_{2}$ and $\mathrm{Pt}-\mathrm{Rh} / \mathrm{HfO}_{2}$ nanocomposite thin film electrodes. Microsyst. Technol. 2014, 20, 523-531. [CrossRef]

16. Li, M.; Li, C.; Wang, F.; Zhang, W. Thermodynamic assessment of the Ga-Pt system. Intermetallics 2006, 14, 826-831. [CrossRef]

17. Aubert, T.; Elmazria, O. Stability of langasite regarding SAW applications above $800{ }^{\circ} \mathrm{C}$ in air atmosphere. In IEEE International Ultrasonics, Symposium (IUS), Dresden, Germany, 7-10 October 2012; pp. 2098-2101.

18. Seifert, M.; Rane, G.; Kirbus, B.; Menzel, S.; Gemming, T. Surface Effects and Challenges for Application of Piezoelectric Langasite Substrates in Surface Acoustic Wave Devices Caused by High Temperature Annealing under High Vacuum. Materials 2015, 8, 8868-8876. [CrossRef]

19. Wang, Z.; Yuan, D.; Cheng, X.; Xu, D.; Lv, M.; Pan, L.; Duan, X.; Sun, H.; Shi, X.; Lv, Y.; et al. The growth and properties of $\mathrm{Ca}_{3} \mathrm{TaGa}_{3} \mathrm{Si}_{2} \mathrm{O}_{14}$ single crystals. J. Cryst. Growth 2003, 253, 378-382. [CrossRef]

20. Kugaenko, O.M.; Uvarova, S.S.; Krylov, S.A.; Senatulin, B.R.; Petrakov, V.S.; Buzanov, O.A.; Egorov, V.N.; Sakharov, S.A. Basic thermophysical parameters of langasite $\left(\mathrm{La}_{3} \mathrm{Ga}_{5} \mathrm{SiO}_{14}\right)$, langatate $\left(\mathrm{La}_{3} \mathrm{Ta}_{0.5} \mathrm{Ga}_{5.5} \mathrm{O}_{14}\right)$, and catangasite $\left(\mathrm{Ca}_{3} \mathrm{TaGa}_{3} \mathrm{Si}_{2} \mathrm{O}_{14}\right)$ single crystals in a temperature range of 25 to $1000{ }^{\circ} \mathrm{C}$. Bull. Russ. Acad. Sci. Phys. 2012, 76, 1258-1263. [CrossRef]

21. Fa-Peng, Y.; Shuai, H.; Shujun, Z.; Ting-Feng, M.; Xian, Z. Piezoelectric cross-talk investigation of LGT and CTGS single crystals. In Proceedings of Symposium on Piezoelectricity, Acoustic Waves and Device Applications (SPAWDA), Changsha, China, 25-27 October 2013; pp. 1-4.

22. Roshchupkin, D.; Ortega, L.; Plotitcyna, O.; Erko, A.; Zizak, I.; Irzhak, D.; Fahrtdinov, R.; Buzanov, O. Advanced piezoelectric crystal $\mathrm{Ca}_{3} \mathrm{TaGa}_{3} \mathrm{Si}_{2} \mathrm{O}_{14}$ : Growth, crystal structure perfection, and acoustic properties. Appl. Phys. A 2014, 114, 1105-1112. [CrossRef] 
23. Biryukov, S.V.; Schmidt, H.; Sotnikov, A.; Weihnacht, M.; Sakharov, S.; Buzanov, O. CTGS material parameters obtained by versatile SAW measurements. In 2014 IEEE International Ultrasonics Symposium (IUS), Chicago, IL, USA, 3-6 September 2014; pp. 882-885.

24. Seifert, M.; Menzel, S.B.; Rane, G.K.; Hoffmann, M.; Gemming, T. RuAl thin films on high-temperature piezoelectric substrates. Mater. Res. Expr. 2015, 2, 085001. [CrossRef]

25. Rane, G.K.; Menzel, S.; Seifert, M.; Gemming, T.; Eckert, J. Tungsten/molybdenum thin films for application as interdigital transducers on high temperature stable piezoelectric substrates $\mathrm{La}_{3} \mathrm{Ga}_{5} \mathrm{SiO}_{14}$ and $\mathrm{Ca}_{3} \mathrm{TaGa}_{3} \mathrm{Si}_{2} \mathrm{O}_{14}$. Mater. Sci. Eng. 2015, 202, 31-38. [CrossRef]

26. Peterson, N.L. Advanced metals research corporation. In Diffusion in Refractory Metals; Wright-Patterson Air Force Base, Ohio, Wright Air Development Division, Air Research and Development Command, U.S. Air Force: McCook Field, OH, USA, 1960; pp. 1-76.

27. Touloukian, Y.S.; Powell, R.W.; Ho, C.Y.; Klemens, P.G. Thermophysical Properties of Matter. Volume 1: Thermal Conductivity-Metallic Elements and Alloys; IFI/Plenum Data Corp: New York, NY, USA, 1970.

28. Seifert, M.; Rane, G.K.; Menzel, S.B.; Gemming, T. TEM studies on the changes of the composition in LGS and CTGS substrates covered with a RuAl metallization and on the phase formation within the RuAl film after heat treatment at 600 and $800{ }^{\circ} \mathrm{C}$. J. Alloys Compd. 2016, 664, 510-517. [CrossRef]

29. Wilson, W.C.; Perey, D.F.; Atkinson, G.M.; Barclay, R.O. Passive Wireless SAW Sensors for IVHM. In Proceedings of the 2008 IEEE International Frequency Control Symposium, Honolulu, HI, USA, 19-21 May 2008; pp. 273-277.

30. Rane, G.K.; Menzel, S.; Gemming, T.; Eckert, J. Microstructure, electrical resistivity and stresses in sputter deposited $\mathrm{W}$ and Mo films and the influence of the interface on bilayer properties. Thin Solid Films 2014, 571, 1-8. [CrossRef]

31. De Keijser, T.H.; Langford, J.I.; Mittemeijer, E.J.; Vogels, A.B.P. Use of the Voigt function in a single-line method for the analysis of X-ray diffraction line broadening. J. Appl. Crystallogr. 1982, 15, 308-314. [CrossRef]

32. Wilson, D.F.; Beahm, E.C.; Besmann, T.M.; DeVan, J.H.; DiStefano, J.R.; Gat, U.; Greene, S.R.; Rittenhouse, P.L.; Worley, B.A. Potential Effects of Gallium on Cladding Materials; Oak Ridge National Laboratory: Oak Ridge, TN, USA, 1997.

33. Wendel, J. Thermodynamics and Kinetics of Tungsten Oxidation and Tungsten Oxide Sublimation in the Temperature Interval $200{ }^{\circ} \mathrm{C}-1100{ }^{\circ} \mathrm{C}$. Master's Thesis, Lund University, Lund, Sweden, 2014.

34. Predel, B. Ga-Gd-Hf-Zr; Predel, B., Landolt, H., Börnstein, R., Martienssen, W., Madelung, O., Eds.; Springer: Berlin, Germany, 1996; p. 1413. 